\title{
Antioxidant and anti-inflammatory activities of loquat (Eriobotrya japonica) tea
}

\section{Phyu Phyu Khine Zar ${ }^{1}$, Kozue Sakao ${ }^{2}$, Fumio Hashimoto ${ }^{1,3}$, Akiko Morishita ${ }^{2}$, Makoto Fujiii ${ }^{4}$ Koji Wada ${ }^{1,5}$ and De-Xing Hou ${ }^{1,2 *}$}

${ }^{1}$ Course of Biochemical Science and Technology, United Graduate School of Agricultural

Sciences; ${ }^{2}$ Department of Biochemical Science and Technology; ${ }^{3}$ Department of Horticultural Science, Faculty of Agriculture, Kagoshima University, Kagoshima 890-0065, Japan; ${ }^{4}$ Totsukawa Noujou Ltd Co, Nejime, Kagoshima 893-2503, Japan; ${ }^{5}$ Faculty of Agriculture, University of the Ryukyus, Senbaru, Nishihara 1, Okinawa 903-0213, Japan

Corresponding author: Prof. De-Xing Hou, Faculty of Agriculture, Kagoshima University, Kagoshima 890-0065, Japan

Submission date: October 14, 2013; Acceptance date: November 24, 2013; Publication date: November 28, 2013

\begin{abstract}
Background: Fresh loquat leaves contain several kinds of flavonoids and have been reported to have preventive effects against some human diseases such as diabetes, coughs and ulcers-. Recently, fresh loquat leaves in Japan were processed to a beverage, called loquat tea, after the fresh leaves are roasted at $350^{\circ} \mathrm{C}$ for 30 minutes. However, the scientific evidence supporting the functions of these processed leaves is still minimal.
\end{abstract}

Objective: The aim of this study is to investigate the antioxidant and anti-inflammatory activities of roasted loquat tea extract (LTE) in vitro and in culture cells.

Methods: Bioactive fractions of LTE were separated by column chromatograph. Antioxidant activities were determined by DPPH and ROS assay. Pro-inflammatory mediators cyclooxygenase-2 (COX-2) and prostaglandin $\mathrm{E}_{2}\left(\mathrm{PGE}_{2}\right)$ were determined by Western blot and ELISA assay, respectively. Chemical quantification and characterization were analyzed by HPLC, FR-IR,_and NMR. Phenolic content was measured by Folin-Ciocalteu assay.

Results: The results showed that loquat tea extract (LTE) possessed stronger DPPH scavenging activity than fresh. Cellular data revealed that LTE inhibited the production of reactive oxygen species (ROS), and further suppressed the production of COX-2 and $\mathrm{PGE}_{2}$ in lipopolysaccharide (LPS)-activated RAW 264.7 cells. Chemical quantification and characterization data indicated that LTE contained new bioactive phenolic components that were produced from the roasting processes of fresh loquat leaves. 
Conclusions: Loquat tea made from roasted loquat leaves contained new bioactive phenolic compounds that contribute to its antioxidant and anti-inflammatory activities.

Keywords: Loquat tea, Antioxidant activity, Anti-inflammatory activity, Chemical characterization

\section{INTRODUCTION:}

Loquat (Eriobotrya japonica) belongs to the Rosaceae family. All parts of loquat, such as fruits, leaves, and peels have been reported to have health benefits. In particular, the leaves have a higher flavonoid content than the peel or fruits, with stronger radical scavenging activity [1] and have been reported to have preventive effects against skin diseases, diabetes, chronic bronchitis, coughs, phlegm, ulcers, allergies, and cancer [2,3]. Recently, fresh loquat leaves were processed into a beverage, called loquat tea, after the fresh leaves are roasted at $350^{\circ} \mathrm{C}$ for 30 minutes. However, the scientific evidence supporting the functions is still minimal.

Dietary antioxidants can scavenge reactive oxygen species (ROS), which are implicated in a wide range of human diseases such as atherosclerosis and certain cancers [4]. On the other hand, inflammation is the first physiological defense system and is present in two forms: short term inflammation and long term inflammation. Long term inflammation occurs in many kinds of inflammatory diseases and stimulated macrophages to produce excess amounts of inflammatory mediators, such as prostaglandins $\left(\mathrm{PGE}_{2}\right)$ [5]. COX-2 is one of the most pivotal enzymes, and is induced by proinflammatory stimuli and growth factors (LPS), and it is responsible for the production of $\mathrm{PGE}_{2}$ at the inflammatory sites $[6,7]$. Inhibition of the overproduction of $\mathrm{PGE}_{2}$ in macrophages by inhibiting COX-2 expression may have therapeutic potential in inflammatory diseases.

The aim of the present study was to investigate the antioxidant and anti-inflammatory activities of roasted loquat tea. Therefore, fresh and different fractions of roasted loquat tea were extracted by boiling water according to folk customs. The antioxidant activities from the different fractions of loquat tea extracts (LTE) were compared with fresh loquat leaves by 1diphenyl-2-picrylhydrazyl assay (DPPH) assay in vitro and by dichlorofluorescein-diacetate (DCFH-DA) assay in mouse RAW264.7 cells. Since RAW264.7 cells can be used to mimic a state of oxidative stress and inflammation [5,8], the inhibitory effects on the production of cyclooxygenase-2 (COX-2) and prostagladin $\mathrm{E}_{2}\left(\mathrm{PGE}_{2}\right)$ were further examined in lipopolysaccharide (LPS)-activated RAW 264.7 cells. Finally, the HPLC profiles of LTE and its fractions were compared with the extract of fresh loquat leaves to clarify the bioactive compounds contributing to the antioxidant and anti-inflammatory activities in LTE.

\section{METHODS:}

\section{Fresh and Loquat tea extraction}

Loquat leaves were washed and dried, then roasted at $350^{\circ} \mathrm{C}$ for 30 minutes in a ceramic vessel. Then, for both the fresh and roasted samples, the leaves were boiled at $100^{\circ} \mathrm{C}$ for 15 minutes, and supernatants were collected after centrifugation at $12000 \mathrm{rpm}$ for 5 minutes. The supernatant fluid of roasted leaves ( $\mathrm{M}$ fraction) was then separated by MCI gel column, and A, B, C, and D 
fractions were obtained by eluting with water, $30 \% \mathrm{EtOH}, 50 \% \mathrm{EtOH}$, and $100 \%$ acetone, respectively. According to the antioxidant activity-based purification, the $\mathrm{C}$ fraction was further separated with ODS gel column, and C1-C9 fractions were finally obtained by elution with 10 to $90 \% \mathrm{MeOH}$ (Figure 1A). All of extracts and fractions were evaporated and stored at $-20{ }^{\circ} \mathrm{C}$ until use.

\section{DPPH assay}

The radical scavenging activity of LTE and its fractions were measured by the DPPH (1diphenyl-2-picrylhydrazyl) method [9]. Briefly, ten microliters of each extraction fraction $(1 \mathrm{mg} / \mathrm{ml})$ was mixed with $190 \mu \mathrm{l}$ of $100 \mu \mathrm{M}$ DPPH in 96-well plates and a final concentration of $50 \mu \mathrm{g} / \mathrm{ml}$. The plate was covered with aluminum foil and left for 30 minutes at room temperature, with the samples being mixed every 10 minutes. The absorbance was then measured at $492 \mathrm{~nm}$ with a microplate reader (Thermo scientific Multiscan FC, version 1.00.79). 6-Hydroxy -2,5,7,8tetramethyl chroman-2-carboxylic acid (Trolox), which has high antioxidant capacity, was used as a standard. The percentage activity of DPPH scavenging was calculated with the formula $\left(\mathrm{A}_{0^{-}}\right.$ $\left.\mathrm{A}_{1} / \mathrm{A}_{0}\right) \times 100$ where $\mathrm{A}_{0}$ was the absorbance of the control, and $\mathrm{A}_{1}$ was the absorbance of LTE and its fractions [10].

\section{Cell culture}

Murine macrophage-like RAW 264.7 cells were purchased from RIKEN Bioresource Center Cell Bank of Japan (RCB0535), and cultured at $37^{\circ} \mathrm{C}$ in a $5 \% \mathrm{CO}_{2}$ atmosphere in Dulbecco's Modified Eagle Medium (DMEM) containing 10\% FBS, $1 \%$ of penicillin and streptomycin, and $2 \%$ glutamin. Fetal bovine serum (FBS) was purchased from Equitech-Bio (Kerrville, TX, USA), and LPS (Escherichia coli Serotype 055:B5) was purchased from Sigma (St. Louis, MO, USA).

\section{Cell viability assay}

The cell survival rate was measured by a MTT assay [11]. Briefly, RAW 264.7 cells $\left(2 \times 10^{4}\right.$ cells $/ 100 \mu \mathrm{l}$ ) were seeded into each well of 96-well plates. After an incubation period of 24 hours, the cells were treated with different concentrations of LTE or its fractions for 12 hours. Then, 10 $\mu 1$ of MTT solution $(5 \mathrm{mg} / \mathrm{ml})$ was added to each well. After incubating the cells for another 4 hours, the resulting MTT-formazan product was dissolved by adding $100 \mu \mathrm{l}$ of $0.04 \mathrm{~N} \mathrm{HCl}$ isopropanol solution. The amount of formazan was determined by measuring the absorbance at $595 \mathrm{~nm}$ in a microplate reader (Thermo scientific Multiscan FC, version 1.00.79). The results were expressed as the optical density ratio of the treatment to control.

\section{Measurement of ROS production}

Intracellular ROS were determined using the oxidation-sensitive dichlorofluorescein-diacetate (DCFH-DA) fluorescent dye. RAW 264.7 cells were seeded into 96-well plates at a starting density of $2 \times 10^{4}$ cell/well. After pre-incubation for 24 hours, the culturing medium was replaced with a fresh one. The cells were treated with or without LTE and its fractions for 30 minutes before exposure to LPS $(1 \mu \mathrm{g} / \mathrm{ml})$ for 12 hours, and DCFH-DA with a final concentration of 20 $\mu \mathrm{M}$ was then added for an additional 2 hours. Fluorescence was measured at $485 \mathrm{~nm}$ excitation and $530 \mathrm{~nm}$ emission using a fluorescent Multilable Counter (Perkin-Elmer). The relative 
amount of intracellular ROS production was expressed as the fluorescence ratio of the treatment to control.

\section{Measurement of $\mathrm{PGE}_{2}$ production}

$\mathrm{PGE}_{2}$ in the culture medium was measured with a $\mathrm{PGE}_{2}$ enzyme immunoassay kit (Cayman Co., St. Luris, MO, USA) according to manufacturer's manual [12]. In brief, RAW 264.7 cells $\left(5 \times 10^{5}\right.$ cells) were seeded into each well of 6-well plates. After an incubation period of 24 hours, the cells were starved by being cultured without serum for another 2.5 hours to eliminate the influence of FBS. The cells were then treated with or without LTE and its fractions for 30 minutes before exposure to LPS $(40 \mathrm{ng} / \mathrm{ml})$ for 12 hours. The amount of $\mathrm{PGE}_{2}$ released into the medium was determined by measuring absorbance at $405 \mathrm{~nm}$ with a microplate reader.

\section{Western blot analysis}

Western blotting was performed as described previously [13]. RAW 264.7 (1 x 10 $\left.{ }^{6}\right)$ cells were pre-cultured in 6-cm dish for 21 hours and then starved by being cultured serum-free another 2.5 hours to eliminate the influence of FBS. The cells were treated with LTE and its fractions for 30 minutes and then exposed to LPS $(40 \mathrm{ng} / \mathrm{ml})$ for 12 hours. Equal amounts of lysated protein were separated on SDS-polyacrylamide gel and transferred onto the PVDF membrane. Afterwards, the membrane was blotted at room temperature for 2 hours in blocking buffer and incubated with specific primary antibody overnight at $4{ }^{\circ} \mathrm{C}$, following a three-time wash with TBS-Tween solution. The membrane was further incubated for 1 hour with HRP-conjugated secondary antibodies and washed three times again. Band intensities bound with antibodies were detected by ECL system in a luminivision PRO machine (TAITEC Co., Japan). Antibodies against COX2 and $\alpha$-tubulin were from Santa Cruz Biotechnology (CA, USA).

\section{Chemical quantification and characterization}

Ten microliters of each extract were analyzed using a HPLC unit and a $250 \times 4.6 \mathrm{~mm}$ i.d., Crest Pak $\mathrm{C}_{18}$ T-5 column. The solvent system was a mixture of $0.05 \mu \mathrm{M} \mathrm{H}_{3} \mathrm{PO}_{4}$ in $\mathrm{CH}_{3} \mathrm{CN}(\mathrm{A})$ and $0.05 \mu \mathrm{M} \mathrm{H}_{3} \mathrm{PO}_{4}$ in water (B), with a flow rate of $0.8 \mathrm{ml} / \mathrm{min}$, and the gradient was as follows: 39 minutes $-4 \%$ A ; $96 \%$ B and 6 minutes $-75 \%$ A ; 25\% B. Spectroscopic data from all peaks were accumulated in the range of $200-700 \mathrm{~nm}$, and chromatograms were recorded at $280 \mathrm{~nm}$. C2 fraction separated from roasted loquat leaf extract was detected using a JASCO FT-IR/IRT-3000 ATR-30-Z (Tokyo, Japan) equipped with an ATR attachment. The FT-IR frequencies were detected between 400 and $4000 \mathrm{~cm}^{-1}$. Moreover, the MALDI-TOF-MS was obtained in a 2,5dihydroxybenzoic acid (DHB) matrix in positive ion mode on a Bruker Autoflex Speed/TOF/TOF(Bruker Daltonics, USA/CA) and the ${ }^{1} \mathrm{H}-\mathrm{NMR}$ spectra were determined using a JEOL JNM-ECA600 (Tokyo, Japan). DMSO-d 6 was used as the solvent, and chemical shifts were expressed ppm with reference to tetramethylsilane.

\section{Measurement of phenolic contents}

The concentration of the total phenolic substances was measured according to the previous method with some modification [9]. Briefly, $10 \mu \mathrm{l}$ of LTE or its fractions was mixed with $200 \mu \mathrm{l}$ of $2 \% \mathrm{Na}_{2} \mathrm{CO}_{3}$ in 96 -well plates. After 3 minutes, $10 \mu \mathrm{l}$ of $50 \%$ diluted Folin-Ciocalteu reagent 
was added to each well. The mixture was allowed to stand for 30 minutes at room temperature with mixing every 10 minutes, and then the absorbance was measured at $595 \mathrm{~nm}$ with a microplate reader (Thermo scientific Multiscan FC, version 1.00.79). The gallic acid was used as standard, and the total phenolic content was expressed as a gallic acid equivalent (GAE) in milligrams per gram of LTE or its fractions.

\section{Statistical Analysis}

All data were statistically analyzed by a student's $t$-test. Differences were considered significant for $p<0.05$ and $p<0.01$.

\section{RESULTS:}

\section{In vitro antioxidant activities of fresh and LTE}

Antioxidant activities of fresh leaves and fractions of LTE were examined using a DPPH assay. As shown in Figure 1B, DPPH scavenging activities of fresh (Fresh) and LTE (M) at the concentration of $50 \mu \mathrm{g} / \mathrm{ml}$ were 18.34 and 44.81, respectively. Thus, LTE possessed higher levels of antioxidant activity than fresh loquat leaves. Furthermore, the DPPH value of fraction A, B, C, or D fractionated from LTE (M) were 44.24, 54.00, 69.31, and $25.24 \%$ at the concentration of $50 \mu \mathrm{g} / \mathrm{ml}$, respectively. According to antioxidant activity-guided purification, C fraction was further separated into $\mathrm{C} 1 \sim \mathrm{C} 9$ fractions by ODS gel column. Their DPPH scavenging activities at the concentration of $50 \mu \mathrm{g} / \mathrm{ml}$ were $69.02,75.00,68.52,67.61,65.28$, $38.54,21.44,27.25$, and 49.67\%, respectively (Figure 1C), suggesting that C1 C5 fractions contain higher antioxidant activity than C6 C9. Thus, we chose C2 fraction with highest antioxidant activity as a sample to further studies.

\section{Antioxidant activities of LTE in culture cells}

To investigate whether the LTE also showed antioxidant activity in cellular level, we measured the change of ROS level in LPS-activated RAW 264.7 cells with or without treatment of LTE, using DCFH-DA fluorescent dye. As shown in Figure 2A, LPS induced ROS production (lane 2), and $\mathrm{C}$ fraction showed the highest inhibitory effect on LPS-induced ROS among M, A, B, C, and $\mathrm{D}$ fractions at a concentration of $25 \mu \mathrm{g} / \mathrm{ml}$. We further investigated the inhibitory effects of $\mathrm{C}$ and its C2 fractions on LPS-induced ROS, and found a dose-dependent inhibition of the ROS at the concentration of $0-50 \mu \mathrm{g} / \mathrm{ml}$ (Figure $2 \mathrm{~B}$ ). These data revealed that LTE and its fractions also had antioxidant activity at the cellular level.

\section{Innhibition of LTE on PGE 2 production in LPS-stimulated RAW 264.7 cells}

Since the antioxidant activity of phytochemicals has been considered to link to anti-inflammation [8], we next investigated the anti-inflammatory activities of LTE in mouse macrophage-like cell RAW 264.7, which is a cell model to investigate inflammation mechanisms. As shown in Figure $3 \mathrm{~A}$, LPS-induced $\mathrm{PGE}_{2}$ productions were significantly attenuated by treatment with LTE (M, A, $\mathrm{B}, \mathrm{C}$, and $\mathrm{D})$. Moreover, $\mathrm{C}$ and $\mathrm{C} 2$ fraction strongly inhibited $\mathrm{PGE}_{2}$ production at the concentration range of 100-200 $\mu \mathrm{g} / \mathrm{ml}$ (Figure 3B). In addition, there is no significant difference in the cell viability between the treatments and controls (Figure 3A and 3B). Thus, the inhibitory effects by LTE and its fractions were not caused by their cytotoxicity. 
(A)

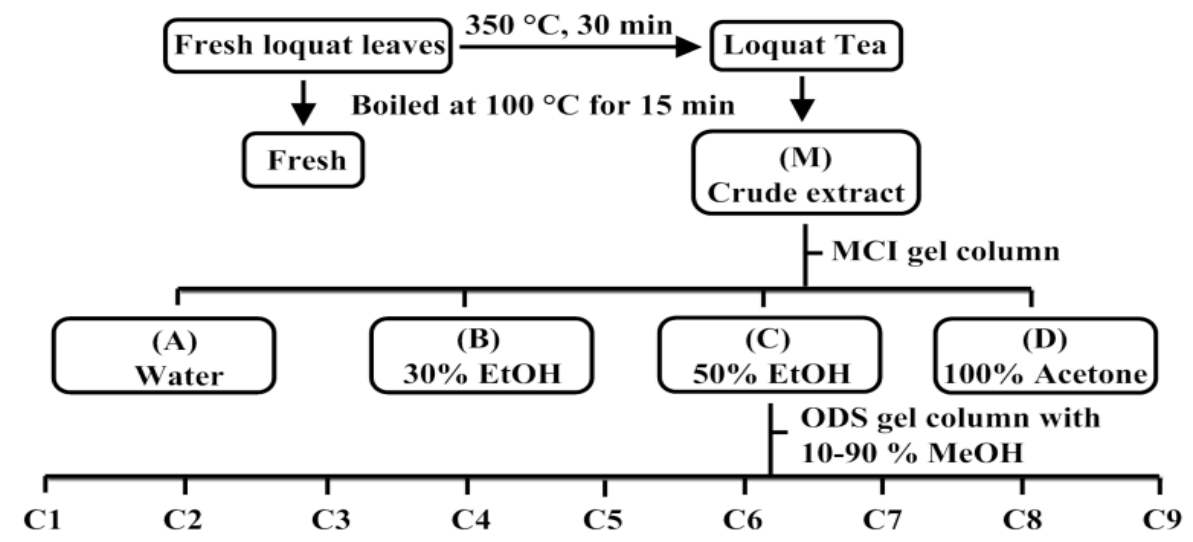

(B)

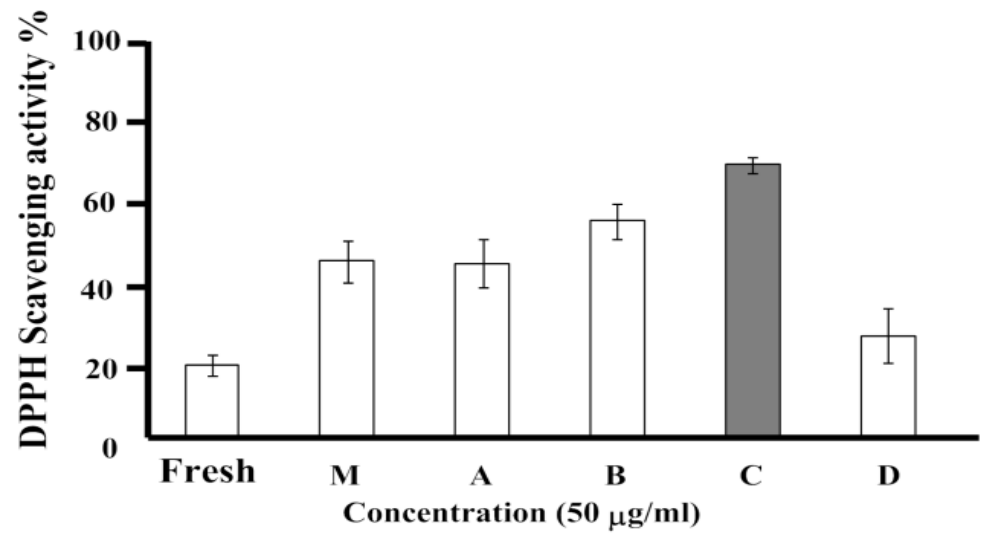

(C)

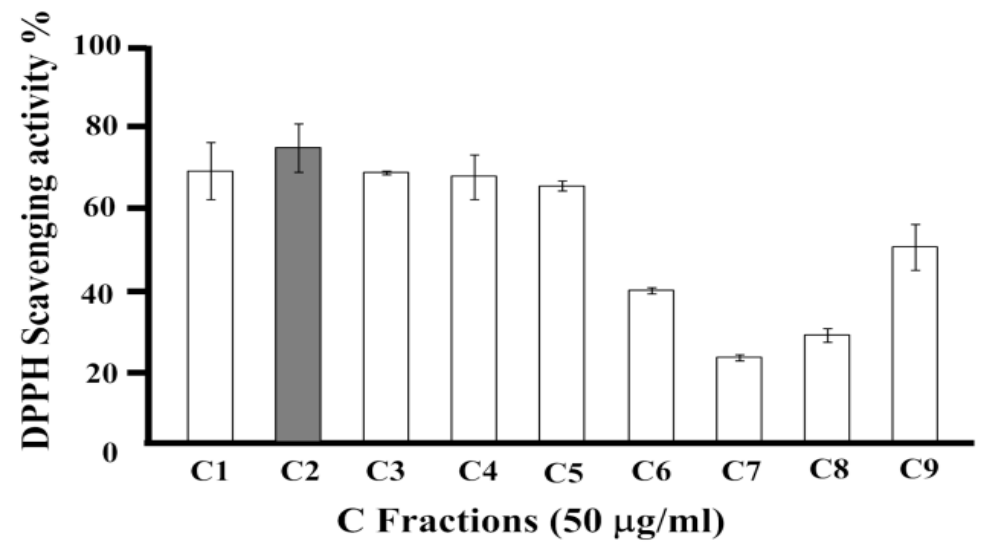

Fig. 1. (A) LTE fractionation. Fresh loquat leaves were roasted at $350^{\circ} \mathrm{C}$ for 30 minutes. Both fresh and roasted leaves were boiled at $100{ }^{\circ} \mathrm{C}$ for 15 minutes. The aqueous layer of roasted leaves was chromatographed by MCI gel column with water, 30\% $\mathrm{MeOH}, 50 \% \mathrm{EtOH}$ and acetone. The fraction which contained high antioxidant activity was further chromatographed by ODS gel column with 10-90\% MeOH. DPPH scavenging activities of fresh loquat leaves and LTE (B), and C1-9 fractions and (C). The values were expressed as the percentage of the control value. $\mathrm{M}$, crude extract; A, water elution fraction; B, 30\% EtOH fraction; C, 50\% EtOH fraction; D, 100\% acetone fraction. C1 C9, fractions 1-9 obtained from $\mathrm{C}$ fraction eluted by $10 \sim 90 \% \mathrm{MeOH}$, respectively. The data represent the mean $\pm \mathrm{SD}$ of three separated experiments. 


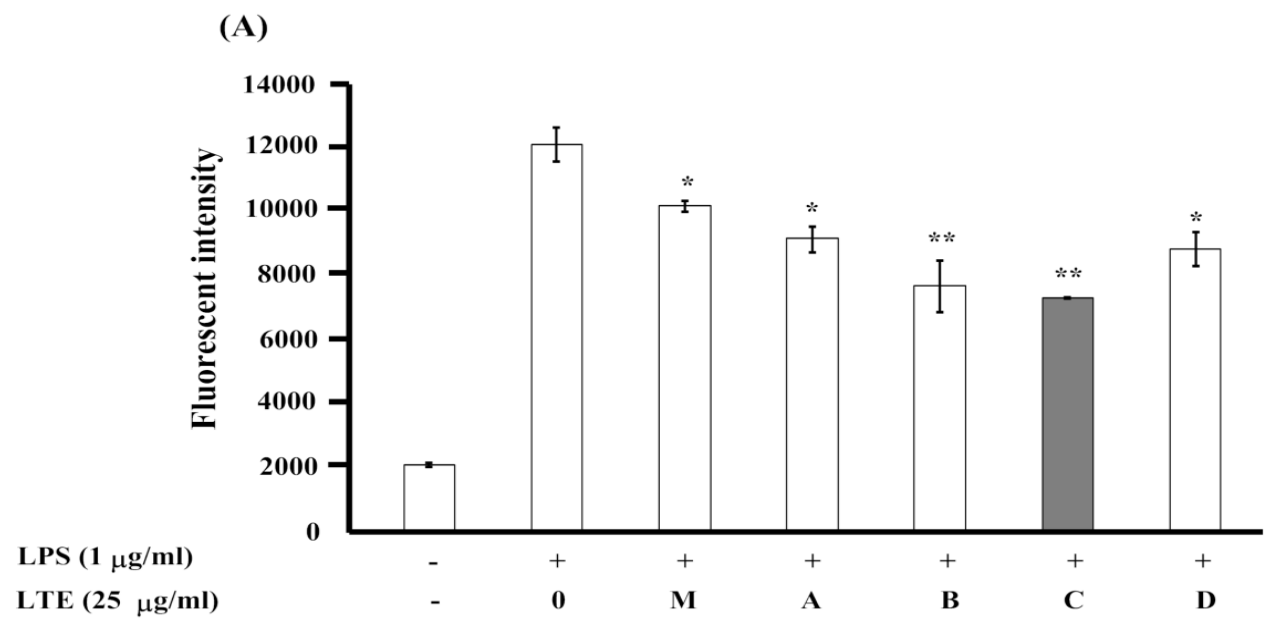

(B)

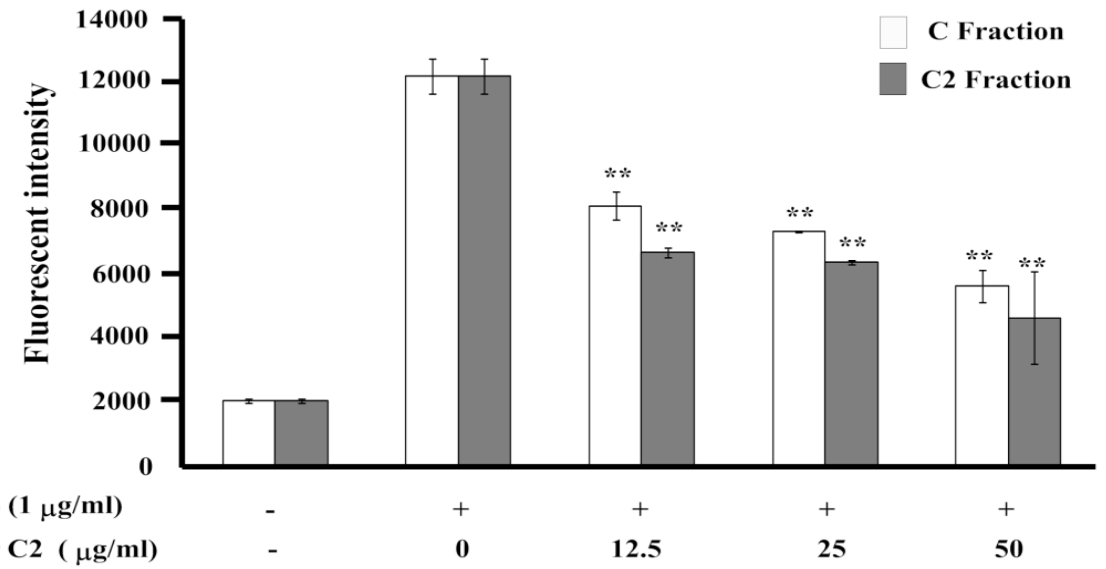

Fig. 2. Iinhibition of LTE (A), C and C2 fractions (B) on ROS production in LPS-activated RAW 264.7 cells. The cells were seeded into 96-well plate $\left(2 \times 10^{4}\right.$ cells/well) and pre-cultured for 24 hours. The cells were treated with or without LTE fractions at different concentrations for 30 minutes before exposure to LPS $(1 \mu \mathrm{g} / \mathrm{ml})$ for 12 hours. DCFH-DA was then added to the medium with a final concentration of $20 \mu \mathrm{M}$ for an additional 2 hours. The fluorescence intensity was then measured at an excitation $(485 \mathrm{~nm})$ and emission $(530 \mathrm{~nm})$ wavelength using a fluorescent Mutilabel Counter (PerkinElmer), and was expressed as the percentage of control in the absence of LPS. Data are the mean \pm SD of three separated experiments. Asterisk shows significant inhibition to LPS only $(P<0.05)$ and $(P<0.01)$.

Inhibition of LTE on COX-2 expression in LPS-stimulated RAW 264.7 cells $\mathrm{PGE}_{2}$ is usually synthesized at inflammatory site by the enzyme, cyclooxygenase-2 (COX-2). Thus, we further investigated the effect of LTE and its fractions on the LPS-induced COX-2 expression. As shown in Figure 4A, LPS-induced COX-2 production was markedly inhibited by LTE at the concentration $(200 \mu \mathrm{g} / \mathrm{ml})$, and $\mathrm{C}$ and $\mathrm{C} 2$ fractions showed a dose-dependent inhibition on LPS-induced COX-2 expression (Figure 4B and 4C). As a control, $\alpha$-tubulin expression was not changed. These results suggested that LTE, especially $\mathrm{C}$ fraction, inhibited $\mathrm{PGE}_{2}$ production by suppressing COX-2 expression. 


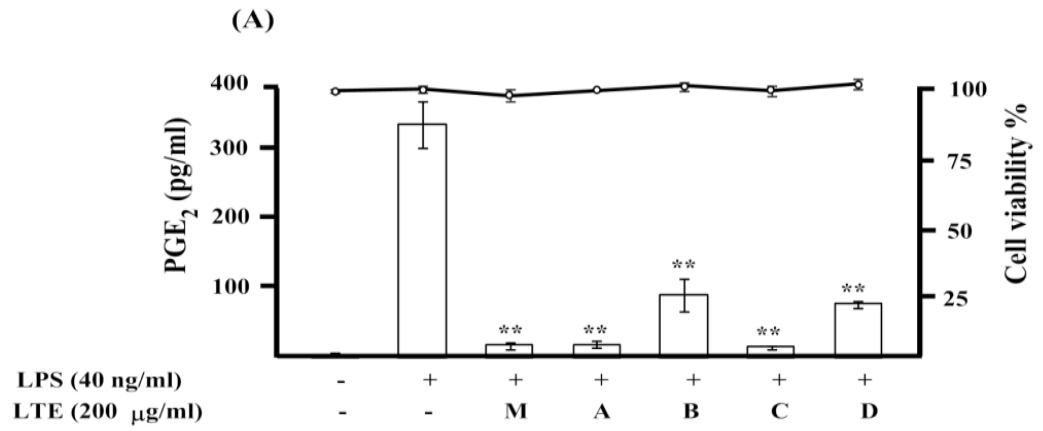

(B)

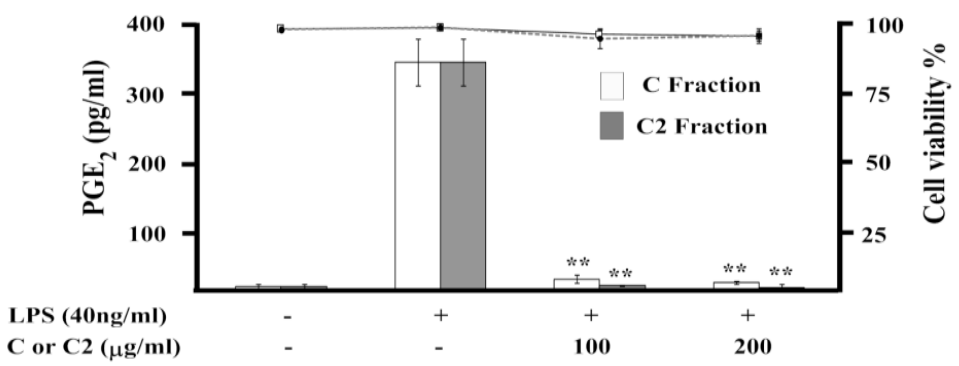

Fig. 3. Inhibition of $\mathrm{PGE}_{2}$ production and influence on cell viability by LTE (A), C fraction and C2 fraction (B) in LPS-induced RAW 264.7 cells. RAW $264.7\left(5 \times 10^{5}\right.$ cells) were pretreated with the indicated concentrations of LTE, C and C2 fractions for 30 minutes and then incubated with LPS (40 $\mathrm{ng} / \mathrm{ml}$ ) for 12 hours. The level of $\mathrm{PGE}_{2}$ production in culture media was determined using enzyme immunoassays (ELISA) kit, and expressed as $\mathrm{pg} / \mathrm{ml}$ (left vertical axis). Asterisk shows significant inhibition to LPS only $(P<0.01)$. The cell viability was simultaneously estimated by MTT assay, and expressed as viability percentage to control cell (right vertical axis). The data represent the mean \pm SD of three separated experiments.

(A)

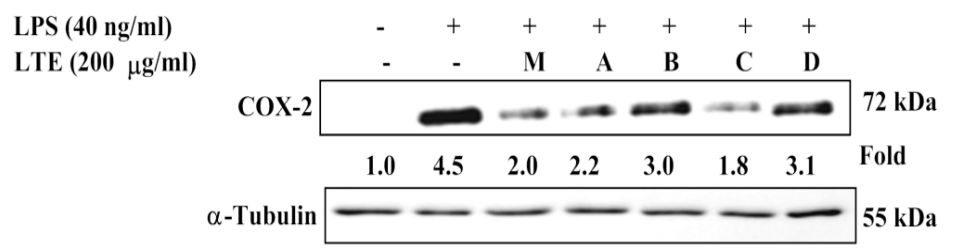

(B)

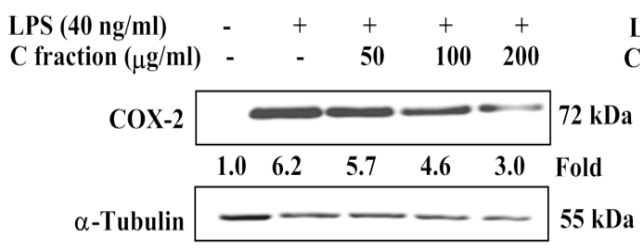

(C)

Fig. 4. Inhibition of LTE (A), C fraction (B) and C2 fraction (C) on COX-2 expression in LPS-activated RAW 264.7 cells. The cells were treated by different fractions of Loquat tea with indicated concentrations for 30 minutes, and stimulated with $40 \mathrm{ng} / \mathrm{ml}$ LPS for 12 hours. COX-2 and $\alpha$-tubulin were detected by Western Blotting and analysis with their antibodies, respectively. The values show the densitometry fold of COX-2 protein normalized to $\alpha$-tubulin. The data represent the mean of three separated experiments. 


\section{Chemical quantification and characterization of LTE}

To analyze the bioactive components in LTE, we first compared the HPLC profiling of LTE to fresh loquat leaves with known compounds as standards. As shown in Figure 5A and Table 1, larger amounts of 5-caffeonylquinic acid and 3-caffeonylquinic acid, and smaller amounts of (-)epicatechin and procyanidin B2 were detected in fresh loquat leaves, but smaller amounts of everything were in LTE crude (b) and none were detected in the C and C2 fraction (c and d) of LTE. Some new peaks were detected (c and d). To characterize these chemicals, C2 fraction was further investigated by FT-IR spectra. The strong and broad band of $\mathrm{O}-\mathrm{H}$ stretching was observed at $3252 \mathrm{~cm}^{-1}$. The existence of one or more aromatic rings in a structure is normally readily determined from the $\mathrm{C}-\mathrm{H}, \mathrm{C}=\mathrm{C}$ and $\mathrm{C}-\mathrm{C}$ ring. Medium strong and finger peaks at 1593 , 1543, and 1515 assigned to $\mathrm{C}=\mathrm{C}$ stretching modes. The generated $\mathrm{C}-\mathrm{C}$ aromatic stretch was observed at 1387.53, with strong absorptions of FT-IR. The peaks at 7193 and $6733 \mathrm{~cm}^{-1}$ could be assigned as mono substitute benzene. These data suggest that some new phenolic compounds might be produced during the roasting process of fresh loquat leaves. Moreover, the $\mathrm{C} 2$ fraction showed primary three peaks at m/z $170-$ m/z 330 on MALDI-TOF MS spectra, and the signals for aromatic or olefinic protons at $6.256-8.308 \mathrm{ppm}$ as well as for the methylene or alicyclic protons at 0.823-2.995 ppm were detected in the ${ }^{1} \mathrm{H}-\mathrm{NMR}$ spectra. Thus, we gather from these data that these compounds in LTE might be several kinds of phenolic compounds.

Since phenolic compounds generally have antioxidant capacity, we thus quantified the phenolic contents of fresh and its fractions of LTE, using gallic acid as reference standard. As shown in Figure 5B, phenolic contents of LTE fractions (M) are higher than fresh loquat leaves. Moreover, the fraction $\mathrm{C}$ and $\mathrm{C} 2$ contained higher phenolic amount among these fractions.

Table1 HPLC data of fresh loquat leaves and roasted loquat tea
\begin{tabular}{|llccc|}
\hline \multirow{2}{*}{ Fractions } & Chemical compound & $\begin{array}{c}\text { Retension time } \\
(\mathbf{m i n})\end{array}$ & $\begin{array}{c}\text { Peak area } \\
(\boldsymbol{\mu} \mathbf{V} . \mathbf{S})\end{array}$ & $\begin{array}{c}\text { Amount } \\
(\mathbf{m g} / \mathbf{k g})\end{array}$ \\
\hline Fresh leaves & 5-caffeonylquinic acid & 21.07 & 1673131 & 6.59 \\
& 3-caffeonylquinic acid & 28.08 & 4225609 & 16.64 \\
& Procyanidin B2 & 31.27 & 295307 & 1.16 \\
& Epicatechin & 36.26 & 1174750 & 4.62 \\
\hline LTE $(\mathbf{M})$ & 5-caffeonylquinic acid & 21.07 & 27036 & 0.26 \\
& 3-caffeonylquinic acid & 28.08 & 106130 & 1.03 \\
& Procyanidin B2 & n.d & - & - \\
& Epicatechin & n.d & - & - \\
\hline LTE $($ C or C2) 5-caffeonylquinic acid & n.d & - & - \\
& 3-caffeonylquinic acid & n.d & - & - \\
& Procyanidin B2 & n.d & - & - \\
& Epicatechin & n.d & - & - \\
\hline
\end{tabular}


(A)
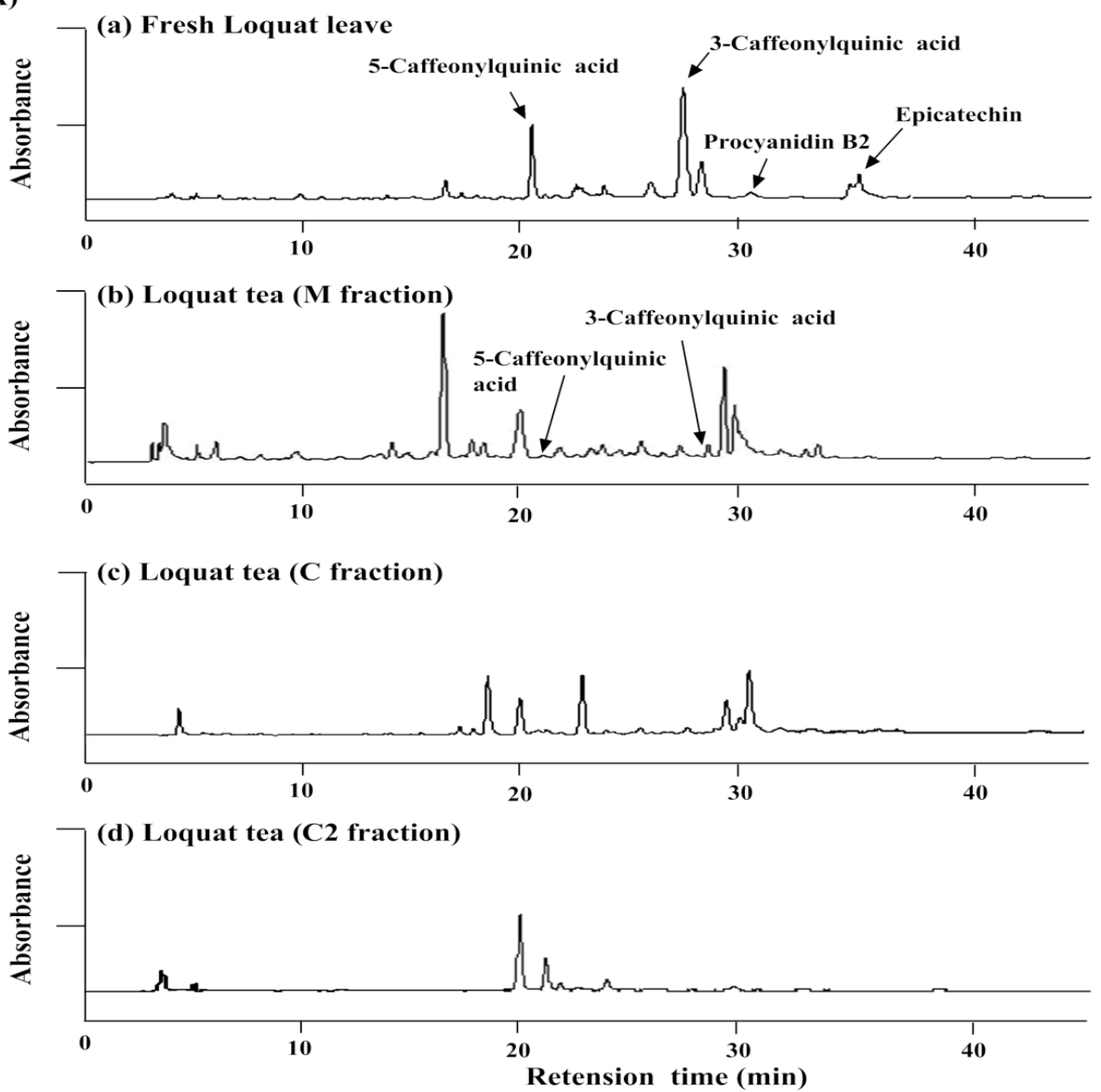

(B)

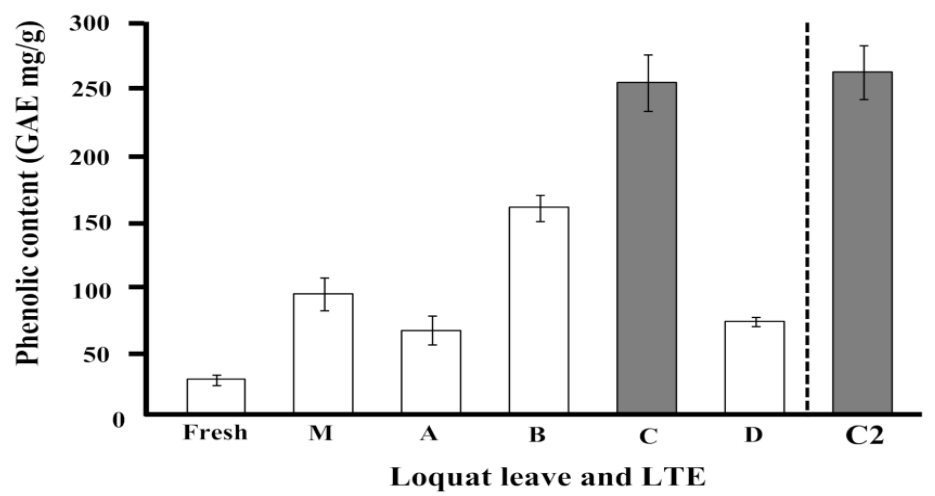

Fig. 5. HPLC profiles (A) of fresh Loquat leave (a), LTE M (b), C fraction (c) and C2 fraction (d). (-)Epicathechin, 3-caffeonylquinic acid, 5-caffeonylquinic acid and procyanidin B2 were used as standards. The CresPak $\mathrm{C}_{18} \mathrm{~T}-5$ column $\left(4.6 \mathrm{~mm}\right.$ i.d. $\times 250 \mathrm{~mm}$ ) was set in $40^{\circ} \mathrm{C}$. Ten microliters of standards or LTE solution was injected to the column after filtered with a millipore filter $(0.45 \mu \mathrm{M})$ and flowed with $0.05 \mathrm{M}$ of $\mathrm{H}_{3} \mathrm{PO}_{4}$ in $\mathrm{CH}_{3} \mathrm{CN}$ from $4 \%$ to $30 \%$ for 39 minutes and then changed $30 \%$ to $75 \%$ for 6 minutes under a flow rate of $0.8 \mathrm{ml} / \mathrm{min}$. Spectroscopic data from all peaks were accumulated in the range of 200$700 \mathrm{~nm}$, and chromatograms were recorded at $280 \mathrm{~nm}$. Phenolic contents $(\mathbf{B})$ of fresh loquat leaf, LTE, LTE and C2 fractions. Phenolic contents were determined by Folin-Ciocalteu method. The amounts were presented as gallic acid equivalents (GAE mg/ml). M, crude extract; A, water elution fraction; B, 30\% EtOH fraction; C, 50\% EtOH fraction; D, 100\% acetone fraction, $\mathrm{C} 2$ fraction purified from $\mathrm{C}$ fraction, respectively. The data represent the mean $\pm \mathrm{SD}$ of three separated experiments. 


\section{DISCUSSION:}

Loquat tea is made from loquat leaves roasted at $350^{\circ} \mathrm{C}$ for 30 minutes, and usually used as beverage according to the folk customs. Although fresh loquat leaves have been reported to have biological activities such as antioxidant and anti-inflammatory activities [14-16], there is no report on the biological activities of roasted loquat leaves (loquat tea). In the present study, we used antioxidant activity-guided fractionation to investigate the biological activities of loquat tea. Our data showed that loquat tea had stronger antioxidant activities than fresh loquat leaves. Loquat tea revealed stronger antioxidant activities not only in vitro, but also in mouse macrophage-like cell RAW264.7, which is a cell model to investigate antioxidant and antiinflammation mechanisms. COX-2 is only induced during inflammation by pro-inflammatory stimuli including bacterial LPS, growth factor and cytokines. COX-2 is the rate-limiting enzyme in the conversion of arachidonic acid to $\mathrm{PGE}_{2}$ which is a pro-inflammatory mediator present in the inflammatory site $[17,18]$. Persistence inflammation and continuous production of COX-2 has been linked to development of cancer and autoimmune disorders [19,20]. In this study, we found that loquat tea could attenuate the production of $\mathrm{PGE}_{2}$ and COX-2 induced by LPS. Therefore, our data indicate that loquat tea has antioxidant and anti-inflammatory properties.

We were then interested in the bioactive compounds contributing to the antioxidant and anti-inflammatory activities in loquat tea extract (LTE). Thus, we compared the HPLC profiles of LTE fractions with the extract of fresh loquat leaves because some bioactive flavonoids such as (-)-epicatechin, 3-caffeonylquinic acid, 5-caffeonylquinic acid, and procyanidin B2 have been clarified in fresh loquat leaves, and have been suggested to contribute the biological activities [21-23].

We confirmed these compounds in fresh loquat leaves using their standard samples (Figure 5A-a). These results are in agreement with the previous report [1, 24]. However, their compounds were much lower in LTE (Figure 5A-b), and finally disappeared in the C and C2 fractions. In place of them, some new compounds were detected in the C fractions (Figure 5A-d). Although we could not determine the chemical structure at this moment, the data from FT-IR spectra showed the existence of aromatic rings and broad band of $\mathrm{O}-\mathrm{H}$ stretching. Moreover, the C2 fraction showed primary three peaks at m/z $170-\mathrm{m} / \mathrm{z} 330$ on the MALDI-TOF MS spectra, and the signals for aromatic or olefinic protons at $6.256-8.308 \mathrm{ppm}$ as well as for the methylene or alicyclic protons at $0.823-2.995 \mathrm{ppm}$ were detected in the ${ }^{1} \mathrm{H}-\mathrm{NMR}$ spectra. Thus, we gather that the bioactive compounds in LTE might be, at least partly, several kinds of phenolic compounds, which are produced from the release and/or degradation of bound phenolic compounds in fresh loquat leaves during roasting process.

Some similar findings have also been reported that (-)-epicatechin and procyanidin significantly decreased after roasting cocoa beans and coca ingredients due to epimerization [25, 26]. Since phenolic compounds have been reported to have antioxidant activities, we next measured the phenolic amount of the $\mathrm{C}$ and $\mathrm{C} 2$ fractions, comparing with LTE using gallic acid as standard. As shown in Figure 5B, phenol content in C and C2 fraction of LTE were $258 \pm$ $22 \mathrm{mg} / \mathrm{g}$ and $267 \pm 21 \mathrm{mg} / \mathrm{g}$. In fresh loquat leaves and LTE (M), the total phenolic contents were $26 \pm 4.2 \mathrm{mg} / \mathrm{g}$ and $77.4 \pm 2.2 \mathrm{mg} / \mathrm{g}$, respectively. These data indicated that phenolic contents were increased when loquat leaves were roasted at $350^{\circ} \mathrm{C}$ for $30 \mathrm{~min}$. It has been reported that high temperature treatment changed phenolic content of samples caused by the release of bound 
phenolic compound, release of phenolic acid derivatives, and thermal degradation of the phenolic compounds [27].

\section{CONCLUSION:}

Loquat tea, made from roasted loquat leaves, revealed stronger antioxidant activity than its fresh leaves by scavenging DPPH and suppressing cellular ROS, and also showed anti-inflammatory activity by suppressing the production of pro-inflammatory mediators such as COX-2 and PGE 2 . The bioactive components are speculated to be phenolic compounds that were produced from fresh loquat leaves during the roasting processes.

\section{Abbreviations:}

LTE, loquat tea extract; COX-2, cyclooxygenase-2; DCFH-DA, dichlorofluorescein-diacetate; DMEM, Dulbecco's Modified Eagle Medium; DPPH, 1-diphenyl-2-picrylhydrazyl; HPLC, High performance liquid chromatography; LPS, lipopolysaccharide; $\mathrm{PGE}_{2}$, prostaglandin $\mathrm{E}_{2} ; \mathrm{ROS}$, reactive oxygen species; Trolox, 6-Hydroxy -2.5.7.8-tetramethyl chroman-2-carboxylic acid.

\section{Competing interest:}

The authors have no financial interests or other conflicts of interest.

\section{Authors' Contribution:}

Ms. Phyu Phyu Khine Zar is the primary investigator in this study. Dr. Kozue Sakao participated in chemical characterization. Dr. Fumio Hashimoto and Dr. Koji Wada participated in the extraction and purification. Ms. Akiko Morishita helped the culture cell experiments. Dr. Makato Fujii helped the preparation of roasted loquat leaves. Dr. De-Xing Hou designed this study and wrote the manuscript as corresponding author.

\section{Acknowledgments:}

This work was supported by the Fund of Scholar Research of Kagoshima University in Japan (to D.-X., Hou).

\section{REFERENCES:}

1. Ferreres F, Gomes D, Valentao P, Goncalves R, Pio R, Chagas EA, Seabra RM at al. Improved loquat (Eriobotrya japonica Lindl.) cultivars: Variation of phenolics and antioxidative potential. Food Chem 2009; 114: 1019-1027.

2. De Tommasi N, Aquino R, De Simona F, Pizza C. Plant metabolites. New sesquiterpene and ionona glycosides from Eriobotrya japonica. J Nat Prod 1992; 55: 1025-1032.

3. Ito H, Kobayashi E, Takamatsu Y, Li SH, Hatano T, Sakagami H, Kusama K, et al. Polyphenols from Eriobotrya japonica and their cytotoxicity against human oral tumor cell lines. Chem Pharm Bull 2000; 48: 687-693.

4. Wootton-Beard PC, Ryan L. Improving public health?: The role of antioxidant-rich fruit and vegetable beverages. Food Res Int 2011; 44: 3135-3148.

5. Laskin DL, Laskin JD. Role of macrophages and inflammatory mediators in chemically 
induced toxicology. J Toxicol 2001; 160: 111-118.

6. Laskin DL, Pendino KJ. Macrophages and inflammatory mediators in tissue injury. Annu Rev Pharmacol Toxicol 1995; 35: 655-677

7. Akira S, Takeda K. Toll-like receptor signaling. Nature Reviews Immunology 2004; 4: 499-511.

8. Su YW, Chiou WF, Chao SH, Lee MH, Chen CC, Tsai YC. Ligustilide prevents LPSinduced iNOS expression in RAW 264.7 macrophages by preventing ROS production and down-regulating the MAPK, NF- $\kappa$ B and AP-1 signaling pathways. Int Immunopharmacol 2011; 11: 1166-1172.

9. Rabah IO, Hou D-X, Komine S, Shono M, Fuji M. Increase in antioxidant and cytotoxicity through apoptosis-induction of HL-60 of sweet potato (Ipomoea Batatas Lam. Cv. Koganesengan) by sub-critical water treatment. Food Sci Technol Res 2005; 11: $122-126$.

10. Xie Z, Huang J, Xu X, Jin Z. Antioxidant activity of peptides isolated from alfalfa leaf protein hydrolysate. Food Chem 2008; 111: 370-376.

11. Hou D-X, Fukuda M, Jonson JA, Miyamori K, Ushikai M, Fujii M. Fisetin induces transcription of NADPH: Quinone oxidoreductase gene through an antioxidant responsive element-involved activation. Int J Oncol 2001; 18: 1175-1179.

12. Hou D-X, Luo D, Tanigawa S, Hashimoto F, Uto T, Masuzaki S, Fujii M et al. Prodelphinidin B-4 3-O-gallate, a tea polyphenol, is involoved in the inhibition of COX-2 and iNOS via the downregulation of TAK1-NF- $\mathrm{BB}$ pathway. Biochem Pharmacol 2007; 74: 742-751.

13. Hou D-X, Yanagita T, Uto T, Masuzaki S, Fujii M. Anthocyanidins inhibit cyclooxygenase-2 expression in LPS-evoked macrophages: Strucutre-activity relationship and molecular mechanisms involved. Biochem Pharmacol 2005; 70: 417-425.

14. Banno N, Akihisa T, Tokuda H, Yasukawa K, Taguchi Y, Akazawa H, Ukiya M, et al. Anti-inflammatory and antitumor-promoting effects of the triterpene acid from the leaves of Eriobotrya japonica. Biol Pharm Bull 2005; 28: 1995-1999.

15. Hong Y, Lin S, Jiang Y, Ashraf M. Variations and contents of total phenolic and flavonoids and antioxidant activities in the leaves of 11 Eriobotrya species. Plant Foods Hum Nutr 2008; 63: 200-204.

16. Kim SH, Shin TY. Anti-inflammatory effect of leaves of Eriobotrya japonica correlating with attenuation of p38 MAPK, ERK, and NF- $\kappa$ B activation in mast cells. J Toxicol In Vitro 2009; 23: 1215-1219.

17. O'Sullivan MG, Huggins Jr. EM, Meade EA, DeWitt DL, McFall CE. Lipopolysaccharide induces prostaglandin $\mathrm{H}$ synthase-2 in alveolar macrophages. Biochim Biophys Res Commun1992; 187: 1123-1127.

18. Adelizzi RA. COX-1 and COX-2 in health and disease. J American Osteropathic Association, 1999; 99: S7-12.

19. Fitzpatrick FA. Inflammation, carcinogenesis and cancer. Int Immunopharmacol 2001; 1: 1651-1667.

20. Kubatka P, Ahler I, Ahlersova E, Adamekova E, Luk P, Bojkova B, Markova M. Chemoprevention of mammary carcinogenesis in female rats by rofecoxib. Cancer Lett 
2003; 202: 131-136.

21. Jung HA, Park JC, Chung HY, Kim J, Choi JS. Antioxidant flavonoids and chlorogenic acid from the leaves Eriobotrya japonica. Arch Pharm Res 1999; 22: 213-218.

22. Ito H, Kobayashi E, Li SH, Hatano T, Sugita D, Kubo N, Shimura S et al. Antitumor activity of compounds isolated from leaves of Eriobotrya japonica. J Agric Food Chem 2002; 50: 2400-2403.

23. Bae YI, Jeong CH, Shim KH. Antioxidative and Antimicrobial activities of Epicatechin isolated from leaves of loquat (Eriobotrya japonica). Int Journal Food Science 2005; 10: 118

24. Tanaka K, Tamaru S, Nishizono S, Miyata Y, Tamaya K, Matsui T, Tanaka T, et al. Hypotriacylglycerolemic and antiobesity properties of a new fermented tea product obtained by tea-rolling processing of third-crop green tea (Camellia sinensis) leaves and loquat (Eriobotrya japonica) leaves. Biosci Biotechnol Biochem 2010; 74; 1606-1612.

25. Hurst WJ, Krake SH, Bergmeier SC, Payne MJ, Miller KB, Stuart DA. Impact of fermentation, drying, and roasting dutch procession on flavon-3-ol stereo chemistry in coca beans and coca ingredients. Chem Cent J 2001; 53: 1-5.

26. Kothe L, Zimmermann BF, Galensa R.Temperature influences epimerization and composition of flavanol monomers, dimmers, and trimers during cocoa bean roasting. $\mathrm{J}$ Food Chem 2013; 141: 3656-3653.

27. Ross CF, Hoye CJ, Fernandez-Plotka VC. Influence of heating on the polyphenolic content and antioxidant activity of grape seed flour. J Food Sci 2011; 76: C884-90. 